\title{
Attenuation of pedestrian-induced vibrations in girder footbridges using tuned-mass dampers
}

\author{
Natividad Garcia-Troncoso* (D, Ana Ruiz-Teran and Peter J. Stafford
}

\author{
* Correspondence: nlgarcia@espol. \\ edu.ec \\ Imperial College London, South \\ Kensington Campus, London SW7 \\ 2AZ, UK
}

\begin{abstract}
This article presents a numerical assessment of pedestrian-induced vibrations for a wide range of girder footbridges before and after the installation of tuned-mass dampers (TMD). Realistic pedestrian loads are defined using a stochastic model that represents the key characteristics of pedestrians and their intra- and inter-subject variability with the aim of ensuring an accurate estimation of the dynamic response. A comprehensive set of numerical analyses have been performed considering different cross sections, structural materials, span lengths (up to $100 \mathrm{~m}$ ), and pedestrian flows. The optimal TMD characteristics, number and location, required to reduce the accelerations, down to a level that fulfils serviceability criteria, are identified. Design recommendations for girder footbridges implementing damping devices at the design stage are also included.
\end{abstract}

Keywords: Girder footbridges, Pedestrian loads, Tuned mass damper (TMD), Dynamic analysis, Serviceability, TMD effectiveness

\section{Introduction}

A key challenge for the bridge engineering community is addressing the design of increasingly slender footbridges, some of which also have relatively long spans. The main uncertainties are linked to the vibration problems that can arise in footbridges due to pedestrian traffic. If any of the footbridge natural frequencies lies near the strep frequencies of the pedestrians, resonant effects leading to large response may occur, and cause discomfort to users. In many cases, supplemental damping devices are required to mitigate human-induced vibrations in footbridges. However, these devices are frequently chosen after the structure has been built to mitigate against unintended levels of vibration. There are also situations when they are included at the design stage, but are often designed in an overlay conservative manner.

In recent years, various studies have focused on developing methods to mitigate human-induced vibration in pedestrian bridges, with most of the emphasis being given to vibration in the vertical direction (Fujino et al. 1993; Nakamura 2004; Dallard et al. 2001). However, excessive lateral vibrations registered at the Toda Park bridge

(c) The Author(s). 2020 Open Access This article is licensed under a Creative Commons Attribution 4.0 International License, which permits use, sharing, adaptation, distribution and reproduction in any medium or format, as long as you give appropriate credit to the original author(s) and the source, provide a link to the Creative Commons licence, and indicate if changes were made. The images or other third party material in this article are included in the article's Creative Commons licence, unless indicated otherwise in a credit line to the material. If material is not included in the article's Creative Commons licence and your intended use is not permitted by statutory regulation or exceeds the permitted use, you will need to obtain permission directly from the copyright holder. To view a copy of this licence, visit http://creativecommons.org/licenses/by/4.0/. 
(T-bridge) in Japan (Fujino et al. 1993; Nakamura 2004), the London Millennium Bridge (Dallard et al. 2001), and The Pont de Solferino (also known as Passerelle Léopold-Sédar-Senghor), in Paris (Danbon and Grillaud 2005) resulted in more intense research attention on the analysis of lateral vibrations. The London Millennium Bridge and the Passerelle Léopold-Sédar-Senghor were closed after their inaugurations in 1999 and 2000 respectively to implement damping devices to reduce unexpected severe lateral vibrations. Due to these high-profile cases, the dynamic response in the lateral direction is nowadays also considered during the design of footbridges (Charles et al. 2006; Butz et al. 2007). For lateral vibrations, research has focussed on the "lock-in" effect, which is also referred to as synchronous lateral excitation. This effect is caused when pedestrians synchronize their step frequencies with the frequency associated with the lateral vibration of the structure. Many studies to date have proposed deterministic models for simulating human-induced vibrations in the vertical and lateral directions through a periodic force using Fourier series. Nevertheless, the forces induced by each pedestrian are different in each successive step, and the real loading will depend on different parameters, such as: the physical and anthropometric properties of each pedestrian (weight, height, age, gender), parameters describing the pedestrian walking (speed, and step frequency), the acceleration registered in the bridge at the location where the pedestrian steps (pedestrian-bridge interaction), the pedestrian density, and the route followed by pedestrians as a consequence of the pedestrian-pedestrian interactions within the flow. These have been considered herein through the stochastic load model proposed by Ramos-Moreno et al. (2019). By bounding the vertical and lateral accelerations within the comfort limits (Charles et al. 2006; BSI 2003; ISO 2005), vibrational serviceability problems are avoided. After performing dynamic analyses under pedestrian loads, when excessive accelerations and displacements are obtained, supplemental damping devices may be considered as a solution to control the dynamic response. In recent years, experimental studies based upon field analysis, as well as numerical studies employing finite element methods, have provided useful information about how designers can reduce human-induced vibration in footbridges using damping devices such as tuned mass dampers (TMD), tuned liquid dampers (TLD) and also visco-elastic dampers (Charles et al. 2006). These supplemental devices are being more frequently incorporated into footbridges after construction has finished, as a way to reduce unexpected human-induced vibrations - such as the three-span steel box girder footbridge over the River Wharfe at Wetherby in Yorkshire, England (Jones and Pretlove 1981), and the Pedro e Inés footbridge in Coimbra, Portugal (Caetano et al. 2010).

Many of the studies related to the control of human-induced vibrations in footbridges have been done using supplemental damping devices in existing structures. These studies have been conducted by the analysis of forces induced by a certain number of walking, running or jogging pedestrians (Caetano et al. 2010; Caetano and Cunha 2014). In some cases, when the damping system is introduced during service, the available space to deploy the damping devices is limited leading to the design of special dampers (Meinhardt 2008). Tuned mass dampers have often been selected over alternative damping devices due to their low cost, and high reliability and efficiency in the 
mitigation of vibration under pedestrian loads. Over the last few years, research has been developed to optimize the placement and properties of multiple tuned mass dampers through deterministic approaches in order to reduce human-induced vibration in pedestrian bridges (Krenk et al. 2005; Daniel et al. 2011). However, a rigorous methodology that focusses on the optimal location and the properties of the tuned mass dampers in footbridges, considering the non-linearities induced by the pedestrian loads in the vertical and lateral directions (Ramos-Moreno et al. 2019), is not yet available. Therefore, the novelties of this research work are: (1) the development of a comprehensive study focused on beam footbridges (considering different materials, cross sections, and a wide range of span lengths) using a very sophisticated load and numerical model that, through stochastic analyses considering the intra- and inter-variability of the pedestrian action, the interaction between pedestrians within the crowd flow, the pedestrian-structure interaction, as well as the non-linearities of the pedestrian actions both in vertical and lateral direction; (2) the set of original conclusions and design recommendations obtained from this work. The purpose of the present study is to fill this gap in the literature and to define how and where to position these devices during the design stage in order to reduce the dynamic response in service, comply with serviceability design criteria, and further demonstrate the benefits of TMDs.

To investigate the efficiency of TMDs, the dynamic response is evaluated through numerical analyses, with and without these devices. Building upon previous research, this work aims to facilitate the design of a range of footbridges through a stochastic model of pedestrian traffic and an efficient damper arrangement. The structure of the paper is as follows. Firstly, the problem formulation is presented in which the girder footbridge characteristics, pedestrian load representation, serviceability criteria, and damping devices are described. Secondly, the design methodology outlining how TMDs should be implemented is described. The parametric analyses conducted and presented herein consider the criteria for selecting the properties of the TMDs, span lengths, cross sections types, structural materials, and the types of pedestrian flows as variables. The procedure identifying the locations where the TMDs should be deployed is illustrated, and the effects of implementing different numbers of dampers and their effectiveness are analysed. In addition, a cost comparison between either changing structural parameters (without implementing supplemental damping devices) or employing TMDs as a strategy to mitigate the human-induced vibrations down to admissible levels is provided. Finally, design recommendations are provided.

\section{Problem formulation}

\subsection{Footbridge characteristics}

A set of single-span girder footbridges (Table 1), using a comprehensive set of structural materials (reinforced concrete, pre-stressed concrete, steel, steel and concrete composite sections, timber, aluminium and glass-fibre reinforced polymers-GFRP), is analysed herein. Table 1 includes the most conventional span lengths. Nevertheless, some of the analyses of this paper cover a wider range of spans for purpose of providing more comprehensive description of the response. We investigate the dynamic response of each footbridge under pedestrian loading, with and without implementing 
Table 1 Girder footbridges considered in the parametric study

\begin{tabular}{|c|c|c|c|}
\hline \multicolumn{2}{|c|}{ Deck cross sections } & \multirow{2}{*}{$\begin{array}{c}\begin{array}{c}\text { Span length } \\
\text { (m) }\end{array} \\
10<\mathrm{L}<45\end{array}$} & \multirow{2}{*}{$\begin{array}{c}\text { Depth (m) } \\
\mathrm{h}=\mathrm{L} / 35\end{array}$} \\
\hline בIh & $\begin{array}{l}\text { Section Type 1: Prestressed } \\
\text { concrete slab }\end{array}$ & & \\
\hline & $\begin{array}{l}\text { Section Type 2: Reinforced } \\
\text { concrete slab }\end{array}$ & $5<\mathrm{L}<35$ & $\mathrm{~h}=\mathrm{L} / 25$ \\
\hline 丂 ГIh & $\begin{array}{c}\text { Section Type 3: Prestressed } \\
\text { concrete T-slab }\end{array}$ & $5<\mathrm{L}<35$ & $\mathrm{~h}=\mathrm{L} / 40$ \\
\hline 口ب्य & $\begin{array}{l}\text { Section Type 4: Concrete } \\
\text { box girder }\end{array}$ & $12<\mathrm{L}<45$ & $\mathrm{~h}=\mathrm{L} / 40$ \\
\hline ए & $\begin{array}{l}\text { Section Type 5: Steel box } \\
\text { girder with concrete slab }\end{array}$ & $20<\mathrm{L}<50$ & $\mathrm{~h}=\mathrm{L} / 30$ \\
\hline$\mp \perp I h$ & $\begin{array}{l}\text { Section Type 6: Steel I } \\
\text { beams with concrete slab }\end{array}$ & $10<\mathrm{L}<45$ & $\mathrm{~h}=\mathrm{L} / 30$ \\
\hline$\square-\square I h$ & $\begin{array}{l}\text { Section Type 7: H-shaped } \\
\text { concrete section with timber } \\
\text { decking }\end{array}$ & $5<\mathrm{L}<35$ & $\mathrm{~h}=\mathrm{L} / 35$ \\
\hline पणणा Ih & $\begin{array}{l}\text { Section Type 8: Timber } \\
\text { beams and concrete slab }\end{array}$ & $5<\mathrm{L}<30$ & $\mathrm{~h}=\mathrm{L} / 25$ \\
\hline$\square \square I h$ & $\begin{array}{l}\text { Section Type 9: Aluminium } \\
\text { box girders and concrete } \\
\text { slab }\end{array}$ & $5<\mathrm{L}<25$ & $\mathrm{~h}=\mathrm{L} / 30$ \\
\hline IIIIIn & $\begin{array}{l}\text { Section Type 10: GFRP } \\
\text { beams and concrete slab }\end{array}$ & $5<\mathrm{L}<25$ & $\mathrm{~h}=\mathrm{L} / 40$ \\
\hline
\end{tabular}

TMDs. The deck widths vary between 2 to $5 \mathrm{~m}$. The material properties of the girder footbridges were selected according to the standards shown in Table 2. These footbridges, without supplemental damping devices, were studied by Ramos-Moreno et al. (2019), and it was shown that the serviceability limit state (SLS) of vibration is not satisfied for certain spans for each section type, as the structural frequencies match the pedestrian frequency. It was also reported that the SLS of vibration cannot be satisfied for sections types 9 and 10 by changing the geometry and sectional dimensions. The objective of this work is to show whether the implementation of TMDs could lead to the verification of the vibration criteria for all these cases.

Table 2 Structural materials characteristics of girder footbridges

\begin{tabular}{|c|c|c|c|}
\hline Structural Material & Standard & Young Modulus (GPa) & $\begin{array}{l}\text { Specific weight } \\
\left(\mathrm{kN} / \mathrm{m}^{3}\right)\end{array}$ \\
\hline Reinforced concrete & EC2 (BSI 2011) & 31.0 & 25.0 \\
\hline Prestressed concrete & EC2 (BSI 2010a) & 37.0 & 25.0 \\
\hline Steel & EC3 (BSI 2009a) & 210.0 & 78.5 \\
\hline Timber & EC5 (BSI 2009a; BSI 2010c) & 12.0 & 7.0 \\
\hline Aluminium (Alloy EN AW 6082) & EC9 (BSI 2010b) & 70.0 & 27.0 \\
\hline GFRP & $\begin{array}{l}\text { Eurocomp Handbook } \\
\text { (Clarke 1996) }\end{array}$ & 17.2 & 25.6 \\
\hline
\end{tabular}




\subsection{Pedestrian load representation}

The evaluation of the dynamic response of the girder footbridges is performed considering the stochastic model proposed by Ramos-Moreno et al. (2014, 2017, 2019, 2020) which includes the simulation of pedestrians walking over the deck and considers the different anthropometric characteristics of each pedestrian, the vertical and lateral forces that each step transmits to the structure, the intra- and inter-subject variability, and the pedestrian-pedestrian interactions within the pedestrian flow. Figure 1 summarises the pedestrian model that was adopted in this study. This approach is based on modelling the vertical loads using the model by Butz et al. (2007) and the lateral loads using the inverted pendulum model proposed by Bocian et al. (2012), and Carroll et al. (2013). The social force model proposed by Helbing and Molnar (1995) is considered to simulate the pedestrian flow and crowd interaction. Several experimental tests have been recorded to develop and validate the different pedestrian loads models used herein, such as Charles et al. (2006), Carroll et al. (2013), Townsend (1985), Pizzimenti and Ricciardelli (2005), Živanović et al. (2007), and Ingólfsson et al. (2011). The pedestrian model of Ramos-Moreno et al. (2019) is capable of describing in a realistic way the loads transmitted by each pedestrian.

\subsubsection{Pedestrian inter-variability}

Each pedestrian is sampled from data representing the UK population. The velocity $\left(v_{p}\right)$ of each pedestrian is derived from three different factors (Eq. 1): the free velocity $\left(v_{f}\right)$, based on the anthropometric characteristics (i.e., the age $\left(\mathrm{a}_{\mathrm{p}}\right)$ and the height $\left(\mathrm{h}_{\mathrm{pd}}\right)$, Eq. 2 ), a factor $\left(\phi_{j}\right)$ related to the aim of the journey (1.11 for commuting activities and 0.86 for leisure activities), and a factor $\left(\phi_{d}\right)$ to consider the influence of the pedestrian density ( $\mathrm{d}$ in units of pedestrians per metre square) (Eq. 3). Groups of pedestrians are considered by assigning similar desired speeds to the pedestrians in the group (governed by the slowest in the group) and forcing them to remain within a particular distance of each other.

$$
\begin{aligned}
v_{p} & =v_{f} \phi_{j} \phi_{d} \\
v_{f} & =0.22+1.28 * 10^{-2} a_{p}-1.71 * 10^{-4} a_{p}^{2}+0.55 h_{p d} \\
\phi_{d} & =1-\exp \left[-1.913\left(\frac{1}{d}-\frac{1}{5.4}\right)\right] \\
f_{p} & =0.11+2.11 v_{p}-0.47 v_{p}^{2} \\
w_{s t} & =26.86-37.74 v_{p}+13.37 v_{p}^{2}+4.92 h_{p d}
\end{aligned}
$$

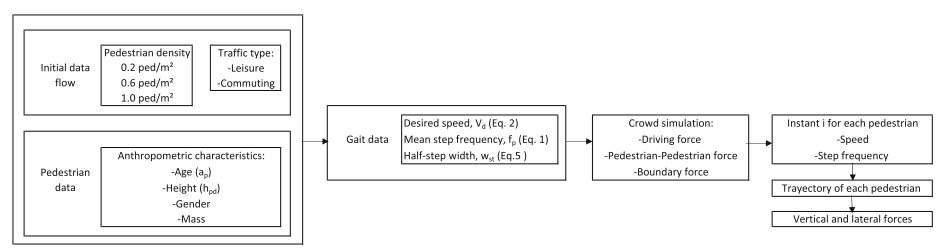

Fig. 1 Pedestrian model of Ramos-Moreno et al. (2019) 
The pedestrian frequency (Eq. 4) is related to the pedestrian velocity, while the free step width $\left(\mathrm{w}_{\mathrm{st}}\right)$ (Eq. 5) is also related to the pedestrian height.

\subsubsection{Vertical loads}

The simulation of vertical loads is based upon the observed temporal distribution of foot loads from empirical studies. Butz et al. (2007) defines the vertical force transmitted through each foot onto the ground through nine key properties defined in Fig. 2, leading to a ninth-degree polynomial (Eq. 6). The coefficients, $\mathrm{p}_{\mathrm{i}}$, of the polynomial can be derived, for any step frequency in Table 3, by solving a system of ten equations (five known points and their derivatives) with ten unknowns. This function describes a double-heap curve for the frequency interval in Table 3, where $\boldsymbol{t}_{\text {end }}$ is the total footground contact time, $\boldsymbol{m}_{\boldsymbol{A}}$ (Eq. 7) is the gradient at the beginning of the step, $\boldsymbol{F}_{\boldsymbol{m a x}, \mathbf{1}} / \boldsymbol{G}$ is the maximum value of the normalized force for the step, $\boldsymbol{F}_{\boldsymbol{m i n}} / \boldsymbol{G}$ is the value at the transition from heel strike to forefoot loading, $\boldsymbol{F}_{\max , 2} / \boldsymbol{G}$ is the value of the normalized force when the pedestrian's foot pushes off the ground, and $\boldsymbol{m}_{\boldsymbol{B}}$ (Eq. 8) is the gradient of the force when the foot is pushing off the ground. The parameters for intermediate frequency values can be obtained through linear interpolation.

$$
\begin{aligned}
& \frac{F(t)}{G}=\sum_{i=1}^{9} p_{i} t^{i} \\
& m_{A}=\frac{F_{\text {min }} / G-0.1}{t_{2}-t_{1}} \\
& m_{B}=\frac{0.1-F_{\text {min }} / G}{t_{4}-t_{3}}
\end{aligned}
$$

As the vertical forces depend on the pedestrian frequency (Table 3) and this in turn on the pedestrian speed (Eq. 1), which is in turn related to the pedestrian density (Eq. 2 and 4), the traffic action, and therefore the structural response, varies non-linearly with the pedestrian density.

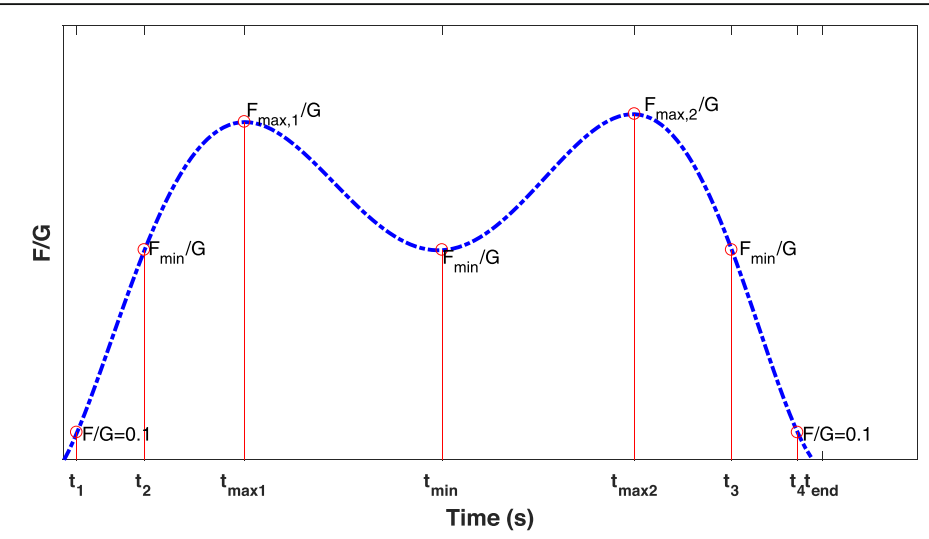

Fig. 2 Parameters required to define the vertical load (F) introduced during the duration of each step, while the foot is in contact with the ground normalized by the pedestrian weight (G) (Butz et al. 2007) 
Table 3 Parameters shown in Fig. 2 to define the vertical loads for different step frequencies

\begin{tabular}{|c|c|c|c|c|c|c|c|c|c|c|c|c|c|}
\hline $\begin{array}{c}\text { Frequencies } \\
(\mathrm{Hz})\end{array}$ & $t_{1}(\mathrm{~s})$ & $t_{2}(\mathrm{~s})$ & $t_{\max , 1}(\mathrm{~s})$ & $t_{\min }(\mathrm{s})$ & $t_{\max , 2}(\mathrm{~s})$ & $t_{3}(\mathrm{~s})$ & $t_{4}(\mathrm{~s})$ & $t_{\text {end }}(\mathrm{s})$ & $m_{A}$ & $F_{\max , 1} / G$ & $F_{\min } / G$ & $F_{\max , 2} / G$ & $m_{B}$ \\
\hline 1.30 & 0.0390 & 0.279 & 0.325 & 0.560 & 0.710 & 0.775 & 0.984 & 1.000 & 4.470 & 1.130 & 1.040 & 1.080 & -4.520 \\
\hline 1.50 & 0.0196 & 0.146 & 0.240 & 0.440 & 0.645 & 0.741 & 0.858 & 0.890 & 6.180 & 1.110 & 0.870 & 1.140 & -6.650 \\
\hline 1.80 & 0.0119 & 0.076 & 0.170 & 0.355 & 0.535 & 0.626 & 0.688 & 0.700 & 10.410 & 1.240 & 0.770 & 1.270 & -10.830 \\
\hline 2.00 & 0.0013 & 0.048 & 0.140 & 0.310 & 0.470 & 0.548 & 0.593 & 0.600 & 12.710 & 1.330 & 0.690 & 1.280 & -13.150 \\
\hline 2.20 & 0.0010 & 0.028 & 0.115 & 0.280 & 0.425 & 0.496 & 0.533 & 0.550 & 19.520 & 1.450 & 0.630 & 1.310 & -14.380 \\
\hline 2.40 & 0.0012 & 0.027 & 0.110 & 0.265 & 0.390 & 0.457 & 0.499 & 0.500 & 19.330 & 1.590 & 0.590 & 1.320 & -11.740 \\
\hline
\end{tabular}

\subsubsection{Lateral loads}

While the lateral ground reaction forces imparted by pedestrians are relatively small compared to the corresponding vertical loads, pedestrians may synchronize their step frequency with the lateral frequency of the bridge, when the lateral accelerations are above certain thresholds, inducing resonant effects. In order to consider the variability of lateral pedestrian-induced loads, which are related to the pedestrian stability while walking, researchers have considered lateral load models described by an inverted pendulum (IP). This model represents a pedestrian's movement in time as a function of the position of the pedestrian centre of mass (CoM) (Ramos-Moreno et al. 2019; Bocian et al. 2012; Ingólfsson et al. 2011) (Fig. 3).

This IP model shows that the CoM movement has a relationship between the gait, the step width, the anthropometric characteristics of the person and the lateral acceleration of the structure in the vicinity of the pedestrian (Macdonald, 2009). Equations (9, 10 and 11 ) are used to define the resulting lateral force $\left(F_{l}\right)$ introduced by the pedestrian on the structure in that particular step.

where: $L_{e q}$ represents the distance from the centre of pressure to the CoM, $m_{p}$ is the mass of the pedestrian, $g$ is gravitational acceleration, $u_{s}$ is the lateral displacement of the structure (therefore $\ddot{u}_{s}$ is the lateral acceleration of the structure in global axes), $w_{s}$ is half of the step width in local axis, $y$ is the position of the CoM in local axis of the deck (therefore $\ddot{y}$ is the acceleration of the CoM in the local axis), $g_{L}$ and $g_{N}$ are the parallel and normal components of the gravitational acceleration. $\Omega_{p}$ is defined as the natural frequency of the lateral movements of the CoM and is given by $\Omega_{p}=\sqrt{\frac{g}{L_{e q}}}$.

$$
g_{N}=\frac{g}{L_{e q}}\left(\omega_{s}-y\right)
$$

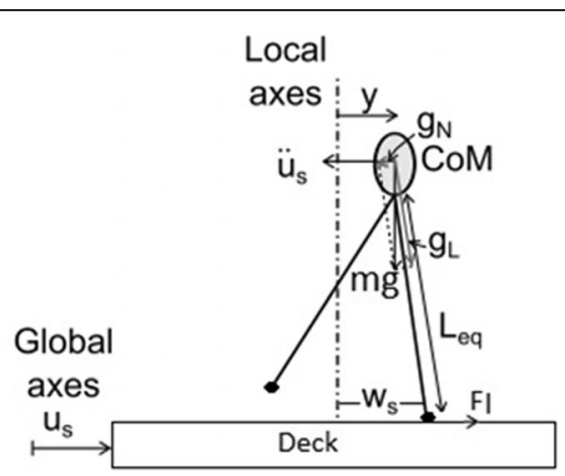

Fig. 3 Inverted pendulum (IP) model (adapted from Ramos-Moreno et al. (2019)) 


$$
\begin{aligned}
& \ddot{u}_{s}+\ddot{y}=-g_{N}=-\frac{g}{L_{e q}}\left(\omega_{s}-y\right) \\
& F_{l}=-m_{p}\left(\ddot{u}_{s}+\ddot{y}\right)=m_{p} \Omega_{p}^{2}\left(\omega_{s}-y\right)
\end{aligned}
$$

As the lateral forces introduced by each pedestrian depend on the acceleration of the deck at the location where the pedestrian steps, and these are induced in turn by the lateral forces applied, the traffic action and therefore the response is non-linearly related to the pedestrian density.

\subsubsection{Crowd modelling}

A social force model for humans was used to consider the human interactions while the pedestrians are crossing the bridge. This model has been applied in transportation, and evacuation studies and also in footbridges (e.g., Carroll et al. 2013; Helbing and Molnar 1995; Jimenez-Alonso et al. 2016). In this social force model, the resultant force $\left(F_{T}\right)$ (Eq. 12), which is needed to describe the pedestrian trajectory at each location, is the sum of the driving force $\left(F_{D}\right)$, and the forces induced by the interaction with other pedestrians $\left(F_{P}\right)$, and by the physical interaction with geometrical boundaries $\left(F_{B}\right)$.

$$
F_{T}=F_{D}+F_{P}+F_{B}
$$

The driving force or motive force is the motivation that the person has to reach the destination (Eq. 13). This is computed from the pedestrian mass $\left(m_{p}\right)$, the desired velocity $\left(v_{d}\right)$, the actual velocity $\left(v_{p}\right)$ and the relaxation time $\left(t_{r}=0.50 \mathrm{~s}\right)$.

$$
F_{D}=m_{p}\left(\frac{v_{d}-v_{p}}{t_{r}}\right)
$$

The interaction among pedestrians is based on the sum of social and physiological forces. The social forces correspond to the pedestrians' willingness to maintain some distance from other pedestrians while crossing the bridge. The physiological forces avoid physical damage from any possible physical contact with other pedestrians, and prevent pedestrians overlapping when the distance between individuals is minimal (as forces relate to pedestrian centroids). The interaction forces induced by boundaries ensures that the pedestrians will keep a certain distance from any obstacle or geometrical constraint such as remaining within the footpath. These three force components in Eq. (12) are clearly defined by Jimenez-Alonso et al. (2016).

\subsubsection{Pedestrian intra-variability}

Each pedestrian crosses the footbridge, starting at an arrival time (following to a Poisson process) and at a lateral position across the deck width (according to a uniform distribution). With these considerations, an initial lateral position and velocity is defined for each pedestrian. A uniform distribution over [0.0, 0.75], where $0.75 \mathrm{~m}$ represents the maximum considered value of step length, is used to represent the initial step position along the deck.

The subject variability (intra-variability) in the step frequency is represented through Markov-Chain Monte Carlo (MCMC) simulation that ensures that individuals vary their step frequency according to some overall distribution, with successive frequencies 
being auto-correlated depending on the value of its magnitude in previous steps (Ramos-Moreno et al. 2019).

The intra-variability in the step width is represented by the lateral movement of the CoM of each pedestrian described by integrating Eqs. (9), (10), and (11) for every step.

For consecutive steps, if the velocity is not affected by external constraints (structural elements or other people defined in the crowd model), then the step frequency for the next step will be computed applying the MCMC methodology. Otherwise, if the pedestrian's velocity is affected by other pedestrians or constraints, through the crowd model, the new pedestrian speed will be calculated, and the new pedestrian frequency will be determined through Eq. (4).

\subsection{Serviceability criteria}

The comfort criteria for the pedestrians crossing the structure is verified by comparing the structural vertical and lateral accelerations to the limits proposed by BSI (2003, 2008), ISO (2005), and the SETRA guidelines (Charles et al. 2006) (Fig. 4). If the dynamic response exceeds these limits, TMDs will be implemented to attenuate the structural accelerations under the limits, and therefore satisfying the serviceability limit state of vibrations.

\subsection{Structural damping}

Several studies have suggested appropriate values of the damping ratio, $\xi$, for footbridges under pedestrian loads. Tilly et al. (1984) showed that it is common to find footbridges having equivalent viscous damping ratios lower than $1 \%$ of critical damping based on tests conducted for several footbridges under pedestrian loading. The work of Bachmann and Weber (1995) showed minimum, maximum and mean damping ratios according to the structural materials of the footbridge. These damping ratios are normal for traffic loads under service conditions, but significantly smaller than those activated under other dynamic actions inducing larger demands in the structure, closer to ultimate limit state. Some researchers and guidelines suggested not to overestimate the structural damping. This is to ensure a conservative analysis of the dynamic analysis response to avoid underestimating the potential dynamic response. The minimum recommended values for the damping factors have been considered for the girder footbridges in this study. This has been strongly recommended by (Heinemeyer and Feldmann
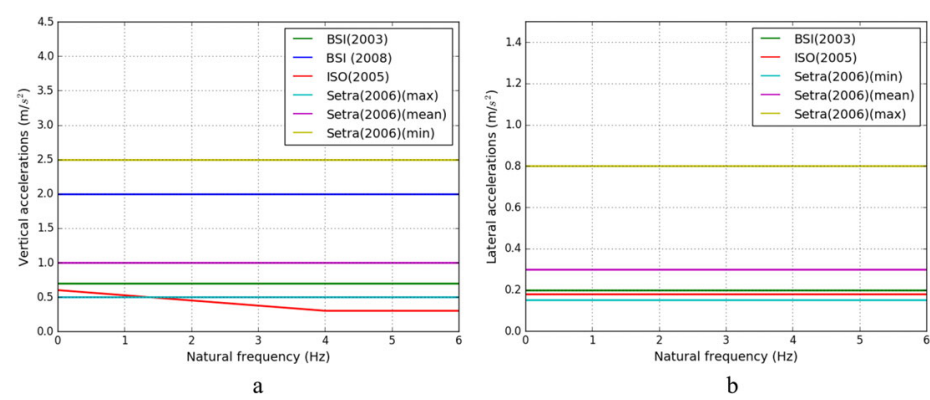

Fig. 4 a Vertical and $\mathbf{b}$ lateral critical accelerations as a function of natural frequency 
2008; Van Nimmen et al. 2014). Therefore, the following values have been chosen (Table 4):

\subsection{Damping devices}

A variety of supplemental damping devices have been used in built footbridges to mitigate vertical and lateral vibrations (Caetano et al. 2010; Caetano and Cunha 2014; Meinhardt 2008). Among them, TMDs are the most frequent type, being reliable, efficient and having a relatively low cost (Schlaich et al. 2005; Low 2008). Out of a dataset compiled by the authors, made of 54 built footbridges with supplemental damping devices implemented to reduced human-induced vibrations, TMDs were the most common type (used in $76 \%$ of the cases), followed by viscous dampers (13\%) and TMD viscous dampers (4\%). Single examples (2\% of the cases) using other devices (such as semi-active TMD MR dampers, telescoping hydraulic dampers, frictional dampers, and tuned liquid dampers) were identified.

Many of the damping devices have been implemented after construction, when geometrical, structural, and aesthetic constraints significantly reduce the number of potential solutions that could have been considered during the design stage. However, damping devices also can be considered within the design stages, facilitating the design of slenderer, yet comfortable, footbridges. Nevertheless, the use of these devices at the design stage is still rare, and additional guidance, code prescriptions, and methodologies are required. Eurocode 1993-2 Part 2 (BSI 2009b) mentions that dampers can be employed to mitigate human-induced vibrations, but it does not provide any design procedure or requirement.

Multiple researchers have proposed different procedures to determine the optimum parameters of TMDs (Table 5) for different scenarios: Soong and Dargush (1997) minimized displacements in un-damped structures under harmonic excitations; Warburton (1982) and Krenk et al. (2005) minimized accelerations in un-damped structures, with the former considering white noise; and Nishihara and Asami (2002) minimized the accelerations in structures with low damping ratios.

Table 4 Damping ratio $(\xi)$ values for further parametric studies

\begin{tabular}{|c|c|c|}
\hline Structural material & $\begin{array}{l}\text { Damping } \\
\text { value }(\xi)\end{array}$ & References \\
\hline Reinforced concrete & $0.8 \%$ & $\begin{array}{l}\text { (Charles et al. 2006; ISO 2005; Bachmann and Weber 1995; } \\
\text { Heinemeyer and Feldmann 2008; Blanchard et al. 1977; } \\
\text { Feldmann et al. 2008; Wei et al. 2019) }\end{array}$ \\
\hline Prestressed concrete & $0.5 \%$ & $\begin{array}{l}\text { (Charles et al. 2006; Bachmann and Weber 1995; Heinemeyer } \\
\text { and Feldmann 2008; Wei et al. 2019) }\end{array}$ \\
\hline Composite (steel and concrete) & $0.5 \%$ & $\begin{array}{l}\text { (Charles et al. 2006; BSI 2003; Bachmann and Weber 1995; } \\
\text { Heinemeyer and Feldmann 2008; Wei et al. 2019) }\end{array}$ \\
\hline Steel & $0.5 \%$ & $\begin{array}{l}\text { (BSI 2003; ISO 2005; Heinemeyer and Feldmann 2008; } \\
\text { Blanchard et al. 1977; Wei et al. 2019) }\end{array}$ \\
\hline Timber & $1.0 \%$ & (Heinemeyer and Feldmann 2008; Feldmann et al. 2008) \\
\hline Aluminium & $0.4 \%$ & (Mevada and Patel 2015; Umashankar et al. 2009) \\
\hline GFRP & $0.7 \%$ & (Živanović et al. 2014) \\
\hline
\end{tabular}


Table 5 Optimal characteristics of the TMDs according to different authors, where $\mu$ is the mass ratio between the mass of the TMD $(m)$ and the structure $(M)$, $a$ is the frequency ratio between the TMD $(\omega)$ and the structure $\left(\omega_{s}\right)$ : and $c$ and $\xi$ are respectively the damping, and damping ratio of the TMD

\begin{tabular}{lll}
\hline Author & Frequency ratio $\mathbf{a}=\boldsymbol{\omega} / \boldsymbol{\omega}_{\mathbf{s}}$ & Damping ratio $\boldsymbol{\xi}=\mathbf{c} /(\mathbf{m} \boldsymbol{\omega})$ \\
\hline Soong and Dargush (1997) & $a_{\text {opt }}=\frac{1}{1+\mu}$ & $\xi_{\text {opt }}=\sqrt{\frac{3}{8} \frac{\mu}{(1+\mu)^{3}}}$ \\
Warburton (1982) & $a_{\text {opt }}=\frac{\sqrt{1+\frac{\mu}{2}}}{1+\mu}$ & $\xi_{\text {opt }}=\sqrt{\frac{\mu\left(1+\frac{3 \mu}{4}\right)}{4(1+\mu)\left(1+\frac{\mu}{2}\right)}}$ \\
Krenk et al. (2005) & $a_{\text {opt }}=\frac{1}{1+\mu}$ & $\xi_{\text {opt }}=\sqrt{\frac{1}{2} \frac{\mu}{(1+\mu)}}$ \\
Nishihara and Asami (2002) & $a_{\text {opt }}=\sqrt{\frac{1}{1+\mu}}$ & $\xi_{\text {opt }}=\sqrt{\frac{3 \mu}{8(1+\mu)}} \sqrt{1+\frac{27 \mu}{32}}$ \\
\hline
\end{tabular}

\section{Design methodology}

In order to determine the optimal criteria to define the TMDs parameters and locations, a comprehensive parametric study was conducted, considering different locations and mass ratios $\mu$ (with typical values in footbridges varying from 0.01 to 0.05 - see Tubino and Piccardo (2015)). An important design objective is minimizing the mass of the TMD, and therefore its size and cost, finding the minimum mass ratio that is required to fulfil the serviceability criteria. It is well known that the position of the TMD has an impact on its efficiency (Nishihara and Asami 2002). The TMD efficiency $\beta$ can be measured as the percentage of the peak acceleration (prior to the implementation of this device) that would be cancelled after its installation. The design constraints set limits on the relative displacement between the TMD and the deck, as well as the deck vertical and lateral accelerations. The numerical procedure adopted in each of the studies performed is as follows:

1. The mass, stiffness and damping matrices of the pedestrian bridges are assembled.

2. The structural modal frequencies and mode shapes are determined for the solution without TMDs. At this stage, potential critical modes of the footbridge under pedestrian loading can be initially identified as those with vertical frequencies in the range of the pedestrian vertical frequencies (see Table 3), and those with lateral and torsional frequencies in the range of the pedestrian lateral frequencies (half of the vertical pedestrian frequency) (Garcia-Troncoso et al. 2017). These modes are likely to have large contributions (point 5 below).

3. The structure is loaded considering the probabilistic pedestrian load model defined in Section 2.2. Different loading scenarios are considered, varying the traffic conditions (such as modelling the pedestrian behaviour at peak hours, called commuting, and also during the weekends and more relaxed situations, called leisure), for different pedestrian densities $\left(0.2,0.6\right.$, and 1.0 pedestrians $\left./ \mathrm{m}^{2}\right)$.

4. The vertical and lateral dynamic response induced by each pedestrian flow is calculated (Clough and Penzien 1993). Multiple simulations are run, with the number of simulations (10) determined through a sensitivity analysis.

5. If the maximum structural accelerations obtained exceed the comfort limits, and therefore do not satisfy the serviceability criteria, TMDs are deployed. The frequency of the TMD is tuned to damp the accelerations induced by that critical mode. The efficiency $\beta$ of this device depends on the ratio between the TMD and 
the structural modal masses $(\mu)$, the ratio between the TMD and the structural frequencies $(\alpha)$, the TMD damping ratio $(\xi)$, and its location. The mass ratio is initially set to 0.01 , being incremented, if necessary, when further analyses are required after point 7. The optimal values $\alpha_{\text {opt }}$ and $\xi_{\text {opt }}$ given by Warburton (1982), Soong \& Dargush (1997), Nishihara and Asami (2002), and Krenk et al. (2005) (see Table 5) have been used in order to select the most efficient TMD to improve the pedestrian comfort.

6. The mass, stiffness and damping matrices are updated including the TMD's properties.

7. The new dynamic response, considering the damping devices, is obtained. Then, the serviceability criteria are checked. If the serviceability criteria are not fulfilled, step 5 is repeated, incrementing the damper mass ratio in an iterative way until the serviceability criteria is finally satisfied.

\section{Numerical model and sensitivity analyses}

A finite element model (developed in Python (VanRossum and Drake 2010), and verified against ABAQUS (2014)) has been developed to evaluate the vertical and lateral dynamic response of a comprehensive set of girder footbridges (Table 1), under several pedestrian flows, with different densities $\left(0.2,0.6,1.0 \mathrm{ped} / \mathrm{m}^{2}\right)$ and aims of the pedestrian journeys (business, commuting or leisure activities), with individual pedestrians being sampled as representatives of the UK population. The simply-supported girder footbridges are represented by using 1-dimensional beam elements located at the sectional centroid. Their length was determined through a sensitivity analysis, covering the range from $\mathrm{L} / 2$ to $\mathrm{L} / 40$, for a given span length (L). Results effectively converged to a solution from L/15 with smaller element lengths not influencing the results. The actions were applied on the deck surface and transferred to the beam element.

In order to define the duration of the numerical simulations, further sensitivity analyses were conducted. At the beginning of each simulation, the first pedestrians enter the footbridge, arriving with the desired pedestrian density. After a while, a steady state response is achieved, and the structure corresponds to a stationary ergodic process. This is when the statistical analysis of multiple different or longer single simulations leads to similar results. Simulations of different durations were analysed, ranging from two to nine times the time expected for an average pedestrian to cross the bridge $\left(t_{a p}\right)$ with the duration measured from the instant when the desired pedestrian density had been already achieved on the structure.

The response converged for a duration of $3 t_{a p}$, and therefore this value was adopted to evaluate the dynamic response in all of these parametric studies.

The impact of assuming that pedestrians can arrive in one or two directions, and the effects of the crowd interaction model were also analysed (Fig. 5). Case 1 does not consider the interaction between pedestrians (i.e. two pedestrians could be at the same location at the same time, or very close to each other, in positions which are not physically possible) while cases 2 to 5 consider the crowd interaction. Figure 6 shows the root mean square (RMS) vertical accelerations for a $1 \mathrm{~s}$ interval (Camara and RuizTeran 2015) for 10 simulations in the five different cases that were considered in Fig. 5. RMS accelerations are calculated in function of the time acceleration ( $\mathrm{t}$ ), and $t_{1}$ and $t_{2}$ which is the time interval (Eq. 14). 
CASE 1 (without crowd interaction)

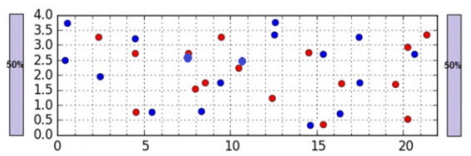

CASE $3(30 \% 20 \%-20 \%-30 \%)$

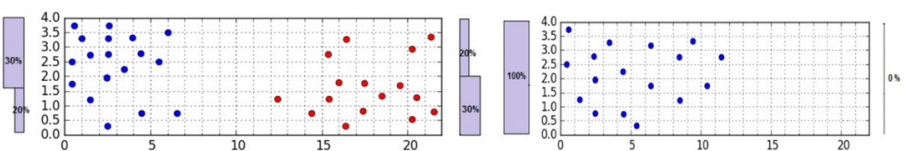

CASE $5(50 \%-50 \%)$

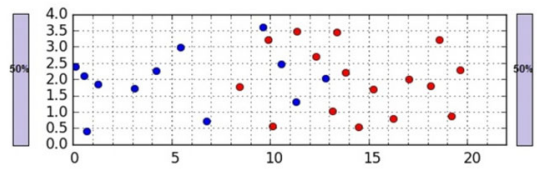

Fig. 5 Plan views of the decks at certain instants, with the centre of masses of the different pedestrians represented in blue and red circles for those pedestrians entering the structure from the left and the right abutments, respectively. The percentages of pedestrians entering the footbridge from each side, and across the width, have been also represented

$$
R M S=\sqrt{\frac{\int_{t_{1}}^{t_{2}} a^{2}(t) d t}{t_{2}-t_{1}}}
$$

Larger responses are achieved when the pedestrians enter the footbridge with a uniform distribution across the width (cases 1,4 and 5). The impact of the direction followed by the crowd and therefore the difference between unidirectional (Case 4) and bidirectional traffic (Case 5) is negligible. For the rest of the analyses in this work, pedestrians arrive in both directions and the crowd model is implemented (Case 5).

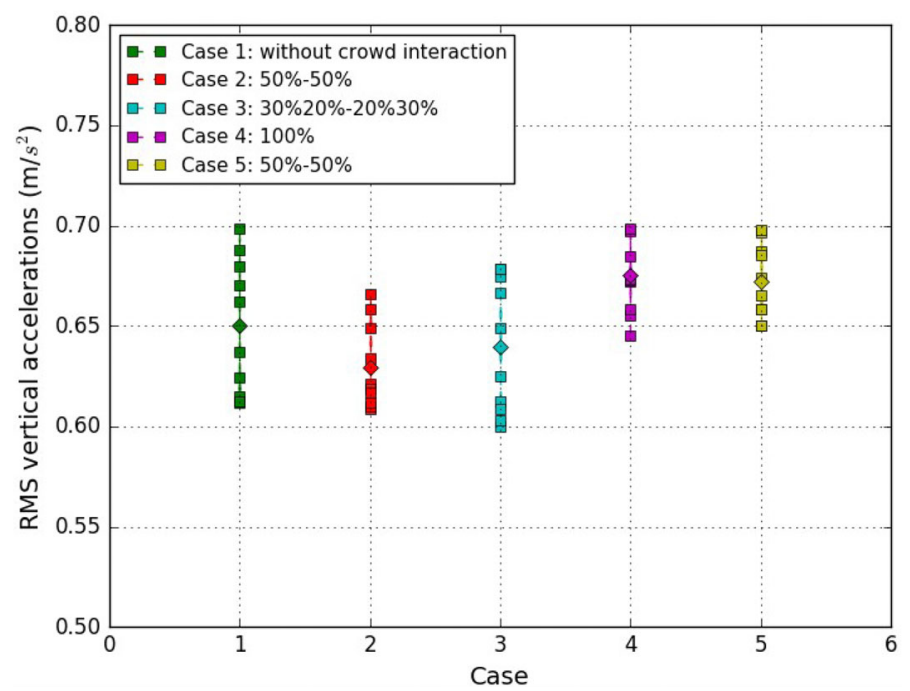

Fig. 6 RMS vertical accelerations for a $1 \mathrm{~s}$ interval at midspan in a simply supported prestressed concrete footbridge ( $L=22.5 \mathrm{~m}$, section type 1) under a pedestrian density of $0.6 \mathrm{ped} / \mathrm{m}^{2}$ for commuting activities. The average of the 10 simulations is highlighted with a diamond marker 


\section{Dynamic response in the vertical direction}

\subsection{Single tuned-mass damper}

As expected, the greatest TMD efficiency is achieved when the TMD is positioned at the location of the maximum nodal coordinates for the modal shape that dominates the response. At that location, the efficiency of the TMD increases and therefore a smaller mass ratio is required to fulfil the serviceability criteria. For the girders considered, the maximum reduction of the dynamic response is achieved when the tuned mass damper is located at mid-span (Fig. 7). Nevertheless, very similar efficiencies are achieved when the TMD is located in the central $30 \%$ of the span ( $\beta$ is equal to $74.50 \%$, $79.40 \%$, and $80.65 \%$, when a TMD is located at $0.35 \mathrm{~L}, 0.40 \mathrm{~L}$, and $0.50 \mathrm{~L}$ respectively for the case considered in Fig. 7). This conclusion is important for design as it gives flexibility to the designers when locating the TMDs. Nevertheless, by shifting the TMD towards the support sections, there is no benefit in reducing the vibrations linked to a second mode, or modes with a zero nodal coordinate at mid-span, as the TMD is not tuned to that modal frequency. Asami's TMD design criteria led to more efficient TMDs, and therefore larger reductions in accelerations, in comparison to the other criteria. Asami's criteria gives larger efficiencies because it was set to minimise the accelerations in structures with low damping, such as in footbridges, where the comfort criteria for these structures is governed by accelerations.

Figure 8 shows the maximum vertical accelerations at mid-span for prestressed (section type 1) footbridges under pedestrian loading (leisure activities) with different span lengths. It is noticeable that for certain span lengths (close to $25 \mathrm{~m}$ ) the serviceability criterion is not fulfilled when TMDs are not implemented, as the frequency of the structure matches the average pedestrian frequency, and a resonant effect is induced. In this case, a single TMD $(\mu=0.04)$ was enough to mitigate the human-induced vibrations. By implementing a TMD designed following Asami's criteria, the accelerations were significantly reduced $(\beta=80 \%$ ), down to the levels. In addition, the TMD also reduces the internal forces by mitigating the dynamic response (see Fig. 9). At resonance, when $\mathrm{L}=25 \mathrm{~m}$, the dynamic component of the bending moments at mid-span is very large, with a dynamic amplification factor (DAF) of 3.27. Nevertheless, the implementation of a TMD reduces the total, and the dynamic bending moments by 31 and $44 \%$

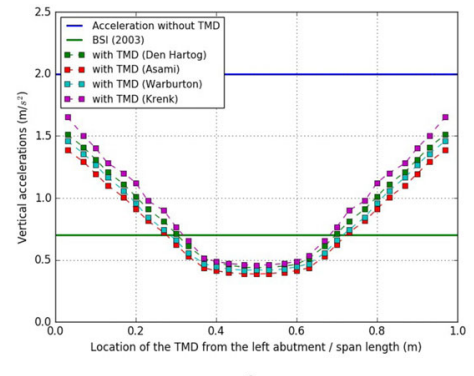

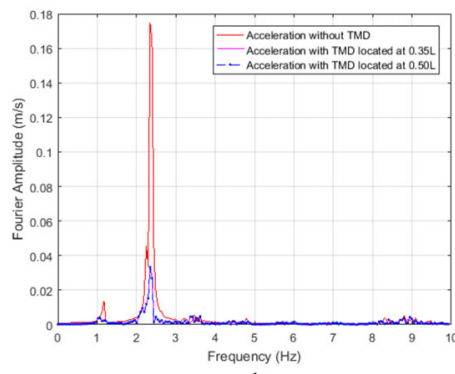

Fig. 7 Simply-supported prestressed concrete (section type 1) footbridge with a $22.5 \mathrm{~m}$ span under pedestrian densities of $0.6 \mathrm{ped} / \mathrm{m}^{2}$ for commuting activities: a peak vertical accelerations at mid-span when a TMD $(\mu=0.05)$ is located at different positions along the length of the bridge, $\mathbf{b}$ Fourier amplitude spectrum of the peak vertical accelerations at mid-span when a TMD $(\mu=0.05)$ located at $0.35 \mathrm{~L}$ and $0.5 \mathrm{~L}$ and when no supplemental damping is implemented 


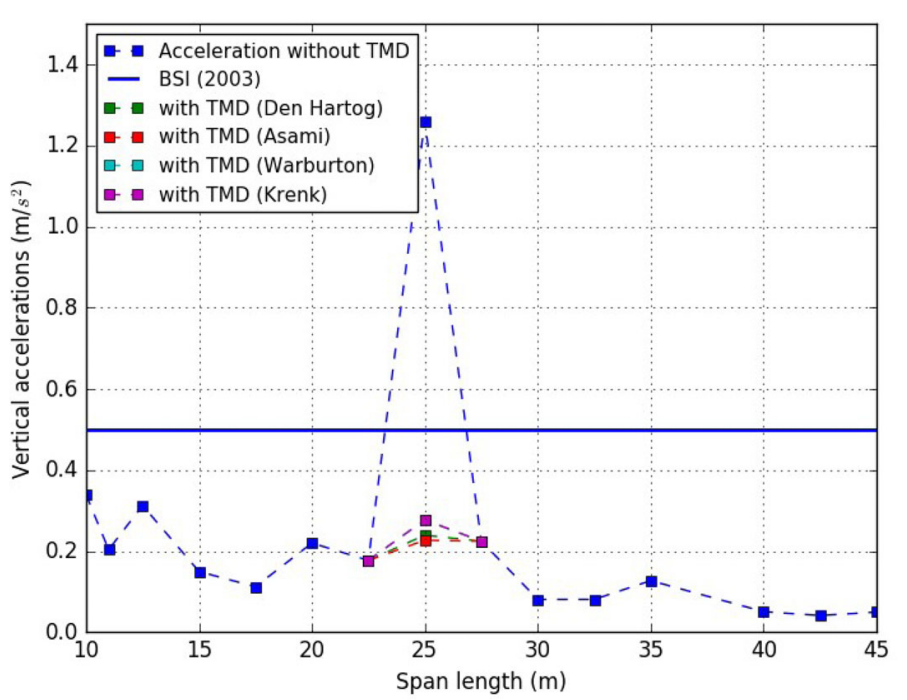

Fig. 8 Maximum peak vertical accelerations for set of prestressed concrete bridges with spans ranging from 10 up to $45 \mathrm{~m}$ for leisure traffics considering different TMD design criteria under pedestrian densities of 0.6 $\mathrm{ped} / \mathrm{m}^{2}$ (leisure activity)

respectively, reducing the DAFs to 2.27. Similar values have been observed for a $12.5 \mathrm{~m}$ span. In this case there is also a resonant effect, with every pedestrian step is resonant with every other vibrational modal cycle.

\subsection{Multiple tuned-mass dampers (MTMDs)}

The same structural type and cross section considered in the previous subsection is analysed herein under commuter traffic. The main critical span is now $22.5 \mathrm{~m}$, rather than $25 \mathrm{~m}$, as a consequence of the increment of the pedestrian frequency (from leisure to commuting) producing resonant effects for higher fundamental structural

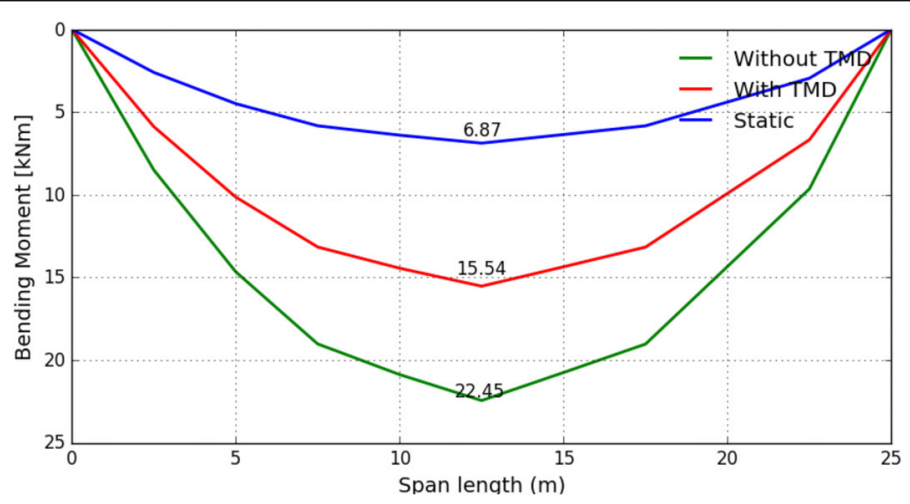

Fig. 9 Maximum dynamic sagging bending moments along the length before and after a TMD $(\mu=0.04)$ was employed at mid-span in a prestressed concrete bridge of a $25 \mathrm{~m}$ span length considering a pedestrian density of $0.6 \mathrm{ped} / \mathrm{m}^{2}$ for leisure activities. The static bending moment induced by the weight of the pedestrians is also represented 


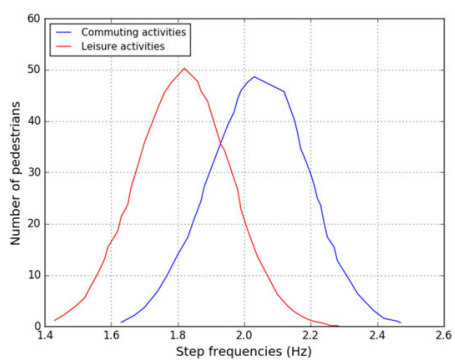

a

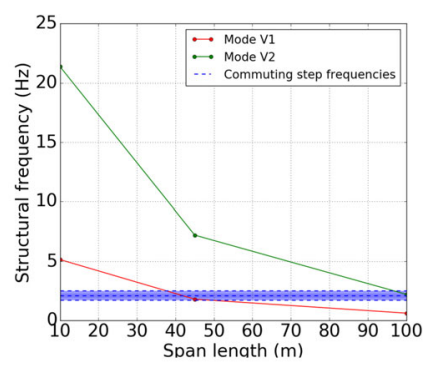

b

Fig. 10 a Distribution of pedestrian frequencies for leisure (red) and commuting (blue) for pedestrian densities of $0.6 \mathrm{ped} / \mathrm{m}^{2}$ for the UK population $\mathbf{b}$ Structural fundamental frequency versus the span length for a prestressed concrete (cross section type 1) footbridge where the blue lines represent the range of vertical frequencies that can be excited by pedestrians

frequencies, i.e., for smaller span lengths (See Fig. 10). The modal shape in Fig. 10b is denoted by $\mathrm{V}$ followed by a number which represents the vertical mode with $\mathrm{N}$-half waves.

One tuned mass damper with a larger mass ratio $(\mu=0.05)$ located at mid-span is now required to mitigate the human-induced vibrations under the comfort limits when $\mathrm{L}=22.5 \mathrm{~m}$ (Fig. 11a). The increment in the mass ratio is due to the increment of the vertical forces (which are frequency related, see Table 3, as well as the small structural mass, leading to larger accelerations as a consequence of Newton's second law. Larger increment of TMD's mass ratios only leads an $8 \%$ reduction in accelerations.

As expected, the serviceability criteria can be fulfilled with a single TMD located at mid-span for bridges up to $50 \mathrm{~m}$ long (Fig. 11b). However, for larger spans of 80 and $100 \mathrm{~m}$, two and four TMDs, respectively, are required at mid-span, leading to total masses in the supplemental damping devices equal to $10 \%$ and $20 \%$ of the structural mass. For larger spans, both the structural mass and the total mass increase, leading to the requirement of significantly larger TMDs (see Table 6). For span lengths longer than 100 (m), the Mode Vertical 2 (V2) become more relevant (Fig. 10b). Therefore, it is required to check in the mode that has a larger contribution in a frequency domain analysis in order to evaluate the optimum location of the TMDs.

In some cases, the geometrical constraints may lead to splitting the TMDs into two during a more detailed stage of the design. When a single TMD is split into two (halving the mass $\mathrm{m}$, the stiffness $\mathrm{k}$ and the damping $\mathrm{c}$, and maintaining the TMD frequency
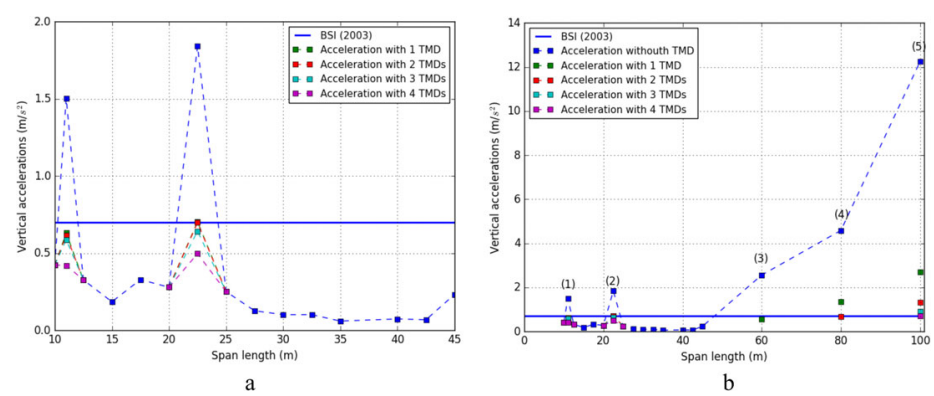

Fig. 11 Maximum vertical peak accelerations for prestressed concrete (section type 1) footbridges with and without TMDs (each of them with $\mu=0.05$ ) with properties defined through Asami's criteria (see Table 6), under pedestrian densities of $0.6 \mathrm{ped} / \mathrm{m}^{2}$ (commuters) for spans ranging from $10 \mathrm{~m}$ (a) up to $45 \mathrm{~m}$, (b) up to $100 \mathrm{~m}$ 
Table 6 Tuned mass damper properties (all with $\mu=0.05$ ) required to mitigate the humaninduced vibrations in the footbridges considered in Fig. $11 \mathrm{~b}$

\begin{tabular}{llllll}
\hline TMD according Fig. 11 & $\begin{array}{l}\text { Number of } \\
\text { dampers }\end{array}$ & $\begin{array}{l}\text { Total TMD } \\
\text { Mass }(\mathbf{k g})\end{array}$ & Length $(\mathbf{m m})$ & Width $(\mathbf{m m})$ & Height (mm) \\
\hline$(1)$ & 1 & 250 & 600 & 560 & 275 \\
$(2)$ & 1 & 1500 & 1000 & 930 & 325 \\
$(3)$ & 1 & 5000 & 2560 & 1410 & 325 \\
$(4)$ & 2 & 4000 & 2000 & 1410 & 325 \\
$(5)$ & 4 & 6000 & 2780 & 1530 & 325 \\
\hline
\end{tabular}

and damping ratio) shifting them longitudinally at both sides of the mid-span, the efficiency of the TMD system is barely affected, as long as they are both still located with the central $30 \%$ of the span length (i.e., $\pm 15 \%$ span from the mid-span). For instance, when $\mathrm{L}=22.5 \mathrm{~m}$, the maximum peak accelerations at mid-span drop from 1.886 to $0.389 \mathrm{~m} / \mathrm{s}^{2}$ introducing one TMD $(\mu=0.05)$ at mid-span, and to $0.411 \mathrm{~m} / \mathrm{s}^{2}$ when two TMDs $(\mu=0.025$ each) are located at $\pm 3 \mathrm{~m}$ from mid-span. This is consistent with the results shown in Fig. 7a. Figure 11b shows that for spans longer than $50 \mathrm{~m}$, the accelerations increase dramatically without supplemental damping devices. Therefore, the number of TMDs that are required to satisfy the comfort limits also increase significantly. Nevertheless, given the size (Table 6) and number of TMDs (Fig. 11b), it is possible to locate all the TMDs required within that central section (i.e., $\pm 15 \%$ span from the mid-span) guaranteeing a large efficiency of the TMD system $(\beta=80 \%)$ and the verification of the serviceability criterion.

\subsection{Cost analysis}

Ramos-Moreno et al. (2019) demonstrated that increasing the slab thickness (i.e., adding mass) was the most efficient way of controlling accelerations with the structural parameters (i.e., without implementing supplemental damping devices) in these types of footbridges. By adding mass, the accelerations are reduced, although this effect could be counteracted by the frequency shift if the structural frequencies get closer to the load frequencies. However, adding mass also increases the structural demands due to self-weight and seismic response, leading to increasing the capacity of several structural members. A comparative cost study between these two design alternatives (implementing TMDs or increasing the slab thickness) is included herein. The unit costs considered are shown in (Table 7) are those from (Bourne 2013) updated by $7.3 \%$ to reflect

Table 7 Material unit costs used in this analysis

\begin{tabular}{lll}
\hline Element & Unit costs (Bourne 2013) (2013) in GBP & Cost rate (2019) in GBP \\
\hline Concrete $\left(\mathrm{m}^{3}\right)$ & 120 & 129 \\
Reinforcement $(\mathrm{t})$ & 1100 & 1180 \\
Prestressing steel $(\mathrm{t})$ & 3000 & 3219 \\
Vertical formwork $\left(\mathrm{m}^{2}\right)$ & 50 & 54 \\
Horizontal formwork $\left(\mathrm{m}^{2}\right)$ & 125 & 134 \\
TMD (unit) & & 3327 \\
\hline
\end{tabular}


the cumulative effects of inflation since the publication of these costs. The TMD considered has a mass of $250 \mathrm{~kg}$, a tuning range from $1.4 \mathrm{to} 2.8 \mathrm{~Hz}$, a damping ratio from 10 to $15 \%$, and a maximum displacement range of $\pm 40 \mathrm{~mm}$, whose unit cost has been provided by a worldwide supplier. Other costs are not considered herein, as the aim is comparing the relative deck material cost for both design alternatives.

The TMD would probably need to be replaced during the footbridge service life. Technical brochures of TMDs highlight that their lifetime is around 20 years (leading to 4 replacements in 100 years). However, this seems very conservative based on recent publications. Weber and Feltrin (2010) and Meinhdart et al. (2017), stated that after 16 years of setup, TMDs still showed a satisfactory performance. The TMDs installed in a footbridge at Frottmanin Subway Station, in Munich, were still working properly 21 years after, and have only required very little maintenance (cleaning and refilling the oil of the damper pot) (Benicke 2017). Therefore, Maurer now recommends one replacement in 100 years, including two maintenance sessions (Benicke 2017). This uncertainty in the number of TMD replacements has been considered in this study, through different TMD life lengths $(20,25,33.3,50$ and 100 years). The same unit cost has been considered for those replacements of TMDs in future years, assuming that the investment (discount) and inflation rates would be similar, as the proper consideration of these additional uncertainties are beyond the scope of this analysis.

The cost analysis (see Fig. 12) has been performed for a prestressed concrete (section type 1) footbridge with an $11.25 \mathrm{~m}$ span length, for different deck depths, considering the design scenario of pedestrian densities of $0.6 \mathrm{ped} / \mathrm{m}^{2}$ (commuters). A deck depth of $\mathrm{L} / 24$ is required to fulfil the serviceability criterion (peak acceleration $\leq 0.7 \mathrm{~m} / \mathrm{s}^{2}$ ) without TMDs, leading to a material cost for the deck of 14,091 GBP. From L/25 to L/35 the solutions with supplemental damping would require the installation of a single TMD at mid-span. Two TMDs would be required for the range from $\mathrm{L} / 39$ to $\mathrm{L} / 43$, and four TMDs for L/49. When TMDs are being used, regardless of the TMD expected life, the smallest material cost is achieved for deck depths of $\mathrm{L} / 35$. If the TMD expected life

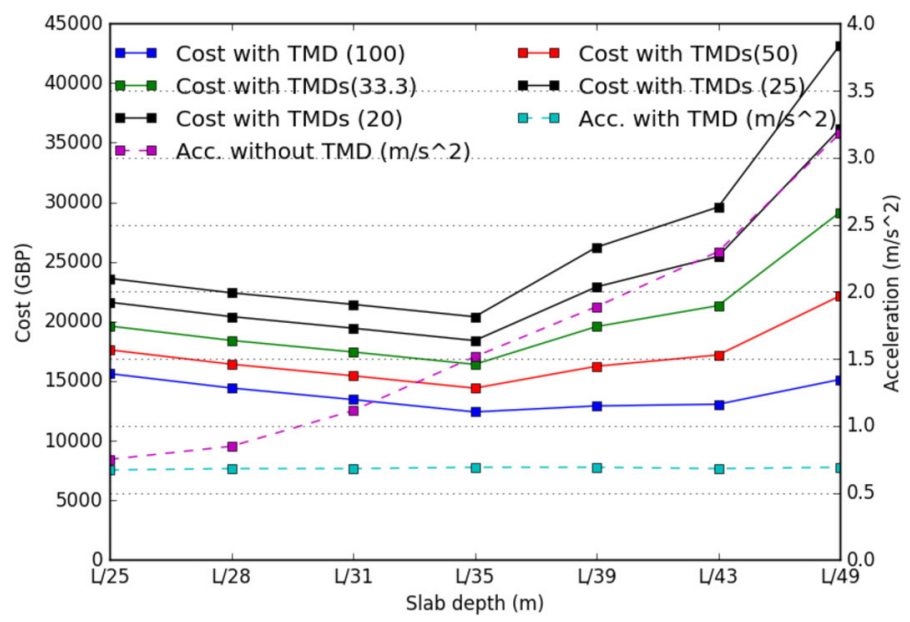

Fig. 12 Cost analysis for different slab thickness $(\mathrm{m})$ when one or multiple TMDs are employed in the design of a prestressed concrete footbridge with a $11.25 \mathrm{~m}$ span length, for different TMD expected lives of $20,25,33.3,50$ and 100 years, with pedestrian densities of $0.6 \mathrm{ped} / \mathrm{m}^{2}$ (commuters) 
can be assumed equal to 100 years, as recommended by (Benicke 2017), then the design with TMDs and deck depth of L/35 would lead to the most economical solution (12\% cheaper than that for L/24 without TMDs), and very small increments would occur for deck depths down to L/43. For shorter expected lives of the TMDs of 50, 33.3, 25 and 20 years, the solutions with TMDs and deck depth of L/35 would be $2 \%, 16 \%, 35 \%$ and $45 \%$ more expensive (for the deck materials) than that for L/24 without TMDs. Nevertheless, there would be additional savings in other structural members such as bearings, abutments and foundations. For deck depths thinner than $\mathrm{L} / 43$ the deck material cost increases significantly.

\subsection{Cross section types}

A comprehensive parametric analysis was undertaken considering all the others section types in Table 1 for different span lengths. Figure 13 shows the structural frequencies for the different section types. It is noticeable that for certain span lengths and materials, the serviceability criterion is not fulfill when TMDs are not employed, showing resonance effects (see peaks in Fig. 14). Therefore, one to four TMDs were located at the maximum nodal displacement of the modal shapes, i.e., at mid-span, to analyse the effect of the reduction of the dynamic response. Furthermore, for longer span lengths, the Mode Vertical 2 (V2) become more relevant.

Table 8 shows the TMD properties (minimum mass of the TMD) that can be employed for each of the resonant cases, activated at particular span lengths. For cross section types 1 to 8 , it is sufficient to employ one tuned-mass damper to satisfy the serviceability criteria. In addition, when a larger number of TMDs is used, there is not a significant reduction of the accelerations. However, for cross sections types 9 and 10, one to four TMDs are not sufficient to control the human-induced vibrations. In these ultra-light cross sections, the serviceability limit state is not fulfilled even when a large number of TMDs are used.

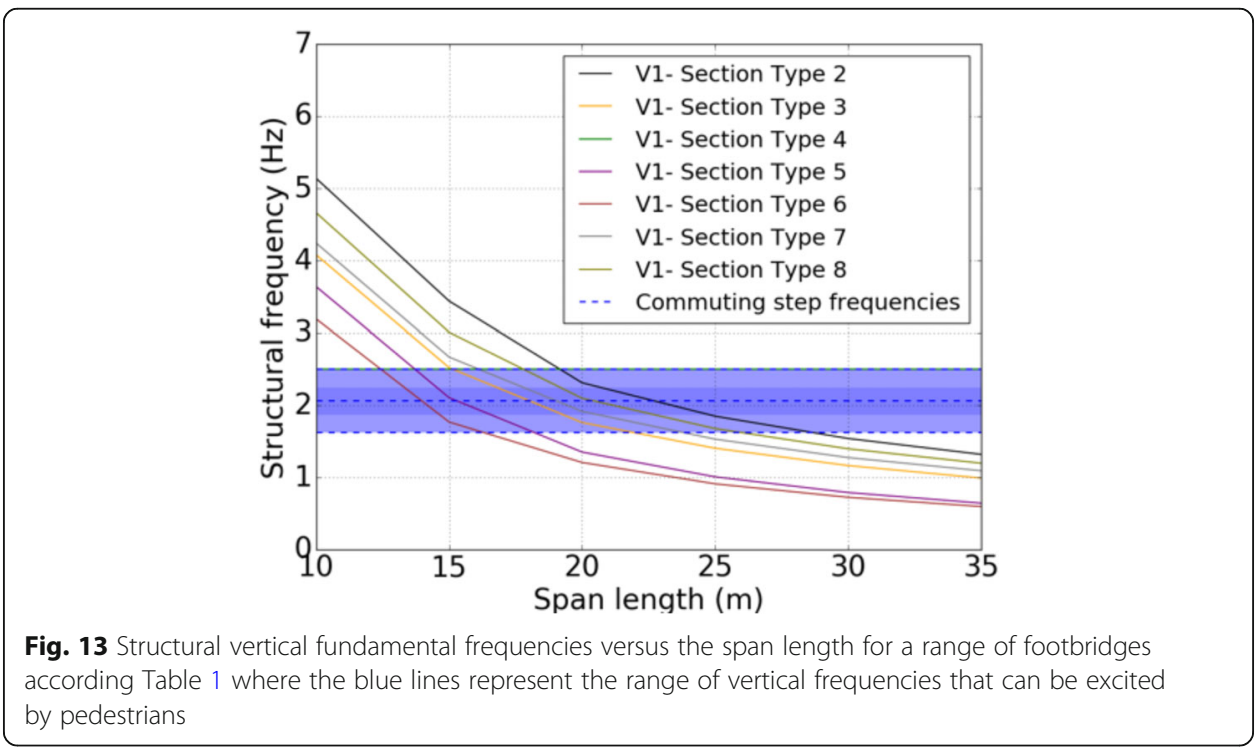



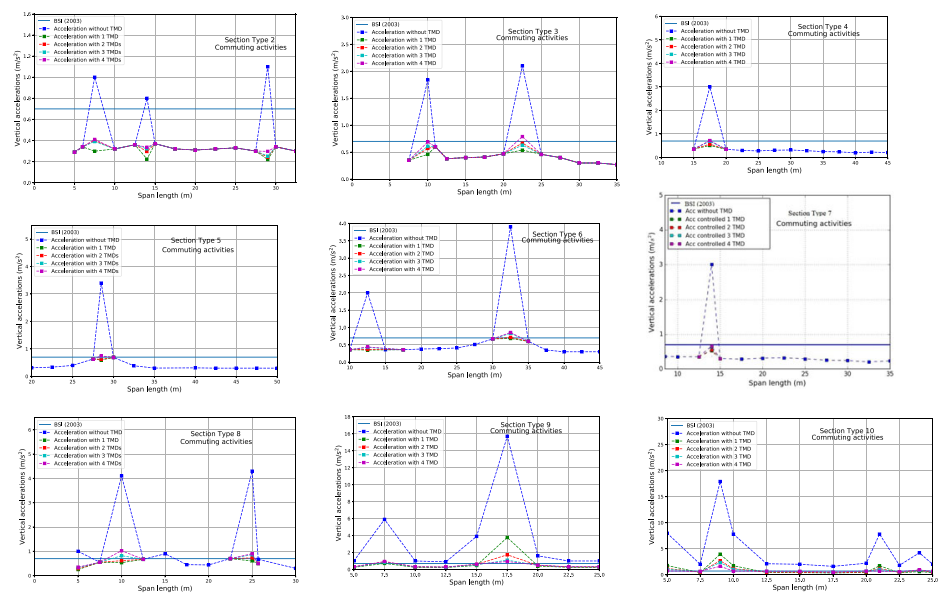

Fig. 14 Maximum vertical accelerations for Section Types 2-10 (Table 1), when one, two, three or four TMDs are implemented at the maximum nodal coordinate of the modal shape with a larger contribution in the dynamic response, under pedestrian densities of $0.6 \mathrm{ped} / \mathrm{m}^{2}$ (commuters)

\section{Dynamic response in the lateral direction}

The lateral peak accelerations increase almost linearly with the span length (see Fig. 15). For given deck widths, these footbridges will have lateral vibration problems above a certain span length. For deck widths equal to $\mathrm{L} / 20$, the limit accelerations are exceeded from span lengths of $20 \mathrm{~m}$. Nevertheless, if the deck width is doubled up to L/10, the serviceability criteria are fulfilled for span lengths from 20 to $100 \mathrm{~m}$. Supplemental damping devices are required for cases in which the deck width is equal to $\mathrm{L} / 20$ to mitigate the lateral human-induced vibrations (Fig. 16 and Table 9). The maximum lateral peak accelerations when one lateral TMD is employed are similar to those when the deck width is doubled and no supplemental damping is used (Fig. 16). Furthermore, if the span length is increased beyond $100 \mathrm{~m}$, the comfort limits will not be satisfied, and lock-in effects will become relevant.

\section{Conclusions}

A very comprehensive range of girder footbridges with different section types, materials, and geometrical configurations (deck depths, widths, and span lengths) were considered to understand their structural response under different pedestrian flows, as well as the benefits in implementing tuned mass dampers (TMD). The conclusions of this research work have been drawn through complex numerical analyses, implementing a realistic description of the pedestrian loading through a stochastic model including pedestrian intraand inter-subject variability, pedestrian-pedestrian interaction (crowd flow) and pedestrian-structure interaction.

The main original conclusions of this study are as follows:

- The greatest efficiency of the TMDs is achieved when the TMD characteristics are determined using Asami's formulations, given the low damping in footbridges and the fact that the comfort criterion is governed by accelerations.

- The larger efficiencies of the TMDs are achieved when they are located at the maximum nodal coordinates of those modal shapes dominating the response. 


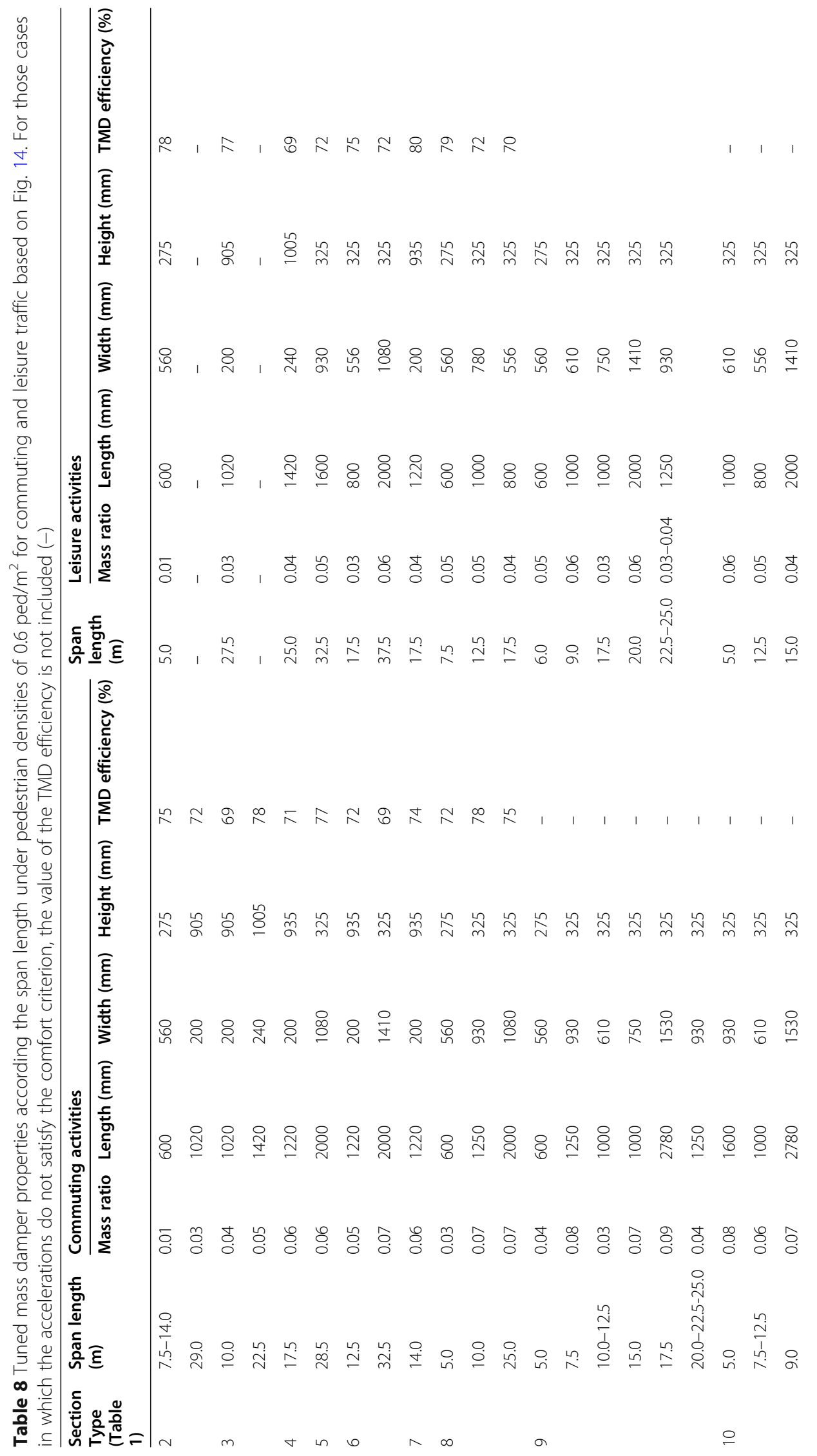




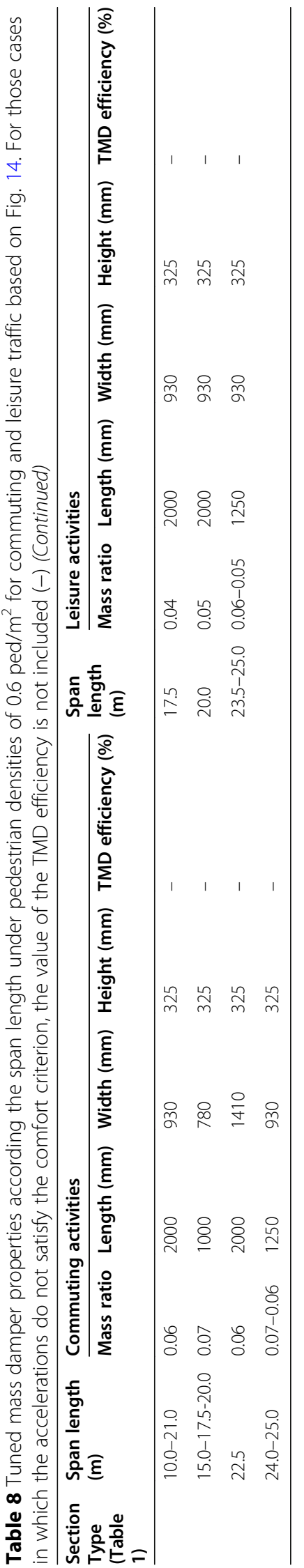




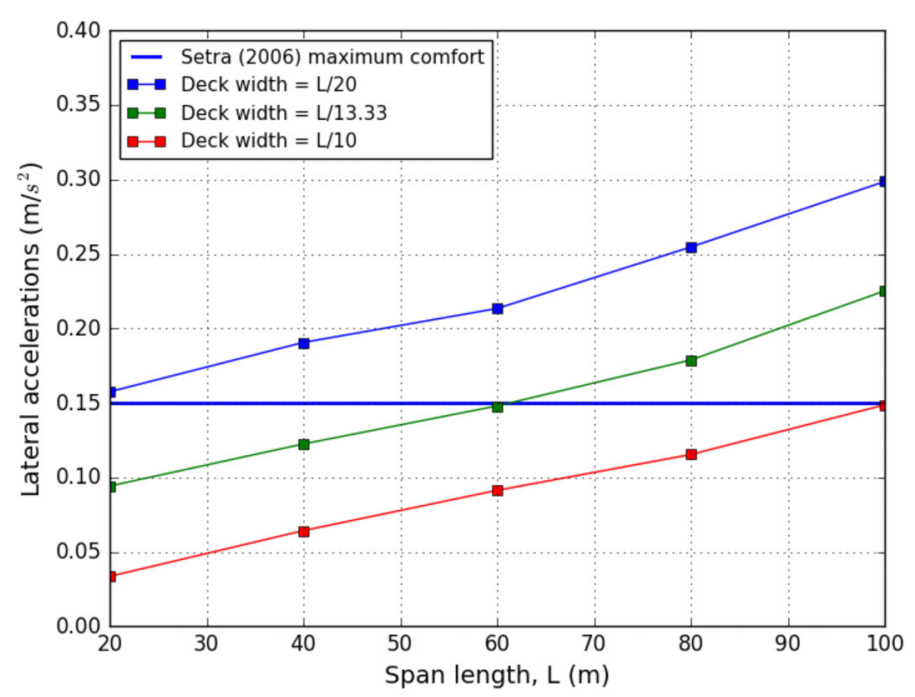

Fig. 15 Maximum lateral peak accelerations in prestressed (section type 1) footbridges under pedestrian densities of $0.6 \mathrm{ped} / \mathrm{m}^{2}$ for commuting traffic

Nevertheless, provided the TMD location remains with the central $30 \%$ of the span length, the high values of the efficiencies, reducing the vertical peak accelerations by up to $80 \%$, are not affected. The implementation of TMDs also reduces the dynamic component of the internal forces, to a lesser extent than for the accelerations.

- For vertical accelerations, the serviceability criteria can be fulfilled with a single TMD, with a 0.05 mass ratio, located at mid-span for bridges up to $60 \mathrm{~m}$ long. However, for larger spans of 80 and $100 \mathrm{~m}$, two and four TMDs, respectively, are required at mid-span, leading to total masses in the supplemental damping devices equal to $10 \%$ and $20 \%$ of the structural mass. Large TMDs can be split into two,

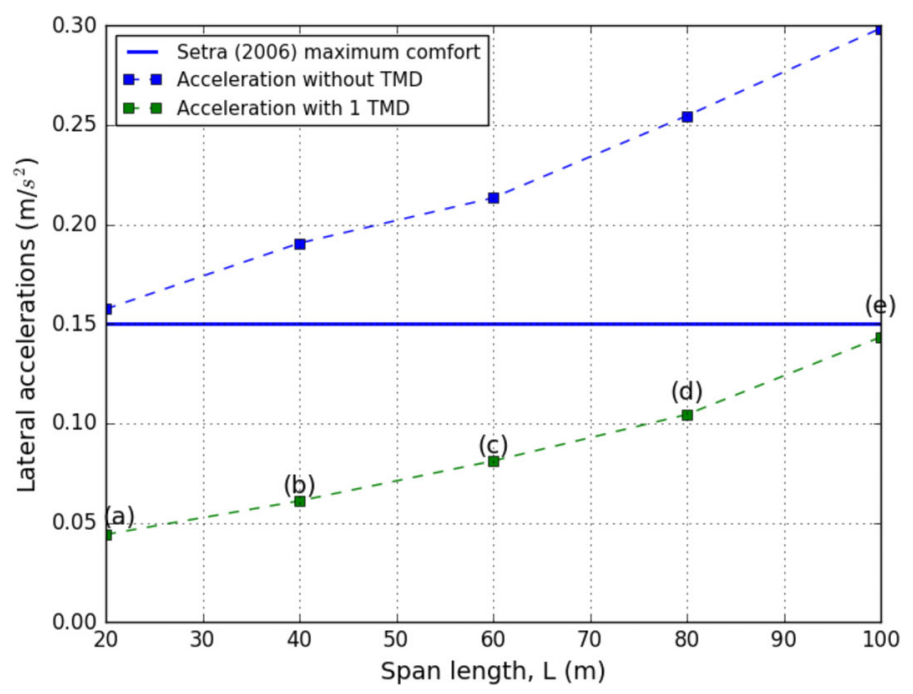

Fig. 16 Maximum lateral peak accelerations for prestressed (section type 1) footbridges under pedestrian densities of $0.6 \mathrm{ped} / \mathrm{m}^{2}$ (commuters) for width/span ratios of $1 / 20$ 
Table 9 Tuned mass damper properties for those TMDs considered in Fig. 16

\begin{tabular}{llllll}
\hline TMD according Fig. 16 & Mass $(\mathbf{k g})$ & Length $\mathbf{( m m})$ & Width $\mathbf{( m m})$ & Height $(\mathbf{m m})$ & TMD efficiency (\%) \\
\hline (a) - (b) & 250 & 880 & 560 & 200 & 72 \\
(c) & 750 & 1330 & 670 & 210 & 71 \\
(d) & 2500 & 1530 & 1200 & 280 & 74 \\
(e) & 5000 & 2140 & 1780 & 310 & 70 \\
\hline
\end{tabular}

provided both remain located in the central $30 \%$ of the span length, with variations of the efficiency of $1 \%$.

- For vertical accelerations, the most cost-effective solution is achieved for deck span ratios of 1/35 when TMDs are used. If the TMD does not need to be replaced, or is replaced only once, throughout the service life, the deck material cost would be smaller, or similar, to the case without TMDs and a deck span ratio of 1/24.

- Vertical accelerations in ultra-light footbridges, with cross sections made of aluminium or glass fibre reinforced polymers, and conventional deck span ratios (1/30 and 1/ 40), do not satisfy the comfort criterion even after implementing multiple TMDs.

Therefore, the slenderness and the structural masses have to be governed by the dynamic response, losing the lightness achieved by implementing these materials. For these structures, the Serviceability Limit State of Vibrations is critical for the design.

- For span lengths up to $100 \mathrm{~m}$, TMDs are not required to control lateral accelerations when the width span ratios are larger than $1 / 10$. However, TMDs are required for span lengths larger than $20 \mathrm{~m}$ when the width span ratios are equal or smaller than 1/20.

Abbreviations

TMD: Tuned mass dampers; GFRP: Glass-fibre reinforced polymers; IP: Inverted Pendulum; CoM: Centre of mass; MCMC: Markov-Chain Monte Carlo; RMS: Root mean square

\section{Acknowledgments}

This research is sponsored by the Secretariat for Higher Education, Science, Technology and Innovation of the Republic of Ecuador (Senescyt) and ESPOL Polytechnic University. Their financial support is gratefully acknowledged. The authors would like to thank Dipl.-Ing. (FH) Oliver Benicke from MAURER Structural Protection Systems for his valuable and constructive suggestions about tuned mass dampers in footbridges.

\section{Authors' contributions}

Literature review, conceptualization, formal analysis, and investigation, NGT; Supervision, AMRT and PJS; Writing - original draft, NGT; Writing - review \& editing, NGT, AMRT, PJS. All authors have read and agreed to the published version of the manuscript.

\section{Funding}

This work was supported financially by the Secretariat for Higher Education, Science, Technology and Innovation of the Republic of Ecuador (Senescyt) and ESPOL Polytechnic University.

\section{Availability of data and materials}

Data are available on request to the authors.

\section{Competing interests}

The author(s) declared no potential conflicts of interest with respect to the research, authorship, and/or publication of this article.

Received: 17 September 2020 Accepted: 26 October 2020

Published online: 30 November 2020

\section{References}

ABAQUS (2014) Dassault Systemes Simulia Corp. Abaqus v. 6.14-2: Analysis User's Guide - Online Documentation Bachmann H, Weber B (1995) Tuned vibration absorbers for "lively" structures. Struct Eng Int 5(1):31-36 Benicke O (2017) Email from MAURER company to Natividad Leonor Garcia Troncoso, 30 November Blanchard J, Davies BL, Smith JW (1977) Design criteria and analysis for dynamic loading of footbridges. In: Symposium on dynamic behaviour of bridges. Transport and Structures Department Road Research Laboratory Bridge Design Division, Crowthorne 
Bocian M, Macdonald J, Burn J (2012) Biomechanically inspired modelling of pedestrian-induced forces on laterally oscillating structures. J Sound Vib 331(16):3914-3929

Bourne S (2013) Prestressing: recovery of the lost art. Struct Eng 91(2):12-22

BSI (2003) BS EN 1991-2:2003. UK National Standard implementation of Eurocode 1: actions on structures - part 2: traffic loads on bridges: BS. British Standards Institution, London

BSI (2008) NA to BS EN 1991-2:2003. UK National Annex to Eurocode 1: actions on structures. Part 2: traffic loads on bridges. BS. British Standards Institution, London

BSI (2009a) BS EN 1995-1:2004. Eurocode 5: design of timber structures. Part 1-1: general-common rules and rules for buildings. BS. British Standards Institution, London

BSI (2009b) BS EN 1993-2:1997. Eurocode 3: design of steel structures. Part 2: steel bridges. BS. British Standards Institution, London

BSI (2010a) BS EN 1993-1:2004. Eurocode 3: design of steel structures. Part 1-1: general rules and rules for buildings. BS. British Standards Institution, London

BSI (2010b) BS EN 1999-1-1:2004. Eurocode 9: design of aluminium structures. Part 1-1: general structural rules. BS. British Standards Institution, London

BSI (2010c) BS EN 338:2009. Structural timber. Strength classes. BS. British Standards Institution, London

BSI (2011) BS EN 1992-1:2004. Eurocode 2: design of concrete structures. Part 1-1: general rules and rules for buildings. BS. British Standards Institution, London

Butz C et al (2007) Advanced load models for synchronous pedestrian excitation and optimised design guidelines for steel foot bridges. European Commission: Research Fund for Coal and Steel

Caetano E, Cunha A (2014) Vibration mitigation of footbridges: case studies. In: London, UK, Footbridge 2014 - past, present and future

Caetano E, Cunha Á, Moutinho C, Magalhães F (2010) Studies for controlling human-induced vibration of the Pedro e Inês footbridge, Portugal. Part 2: implementation of tuned mass dampers. Eng Struct 32(4):1082-1091

Camara A, Ruiz-Teran AM (2015) Multi-mode traffic-induced vibrations in composite ladder-deck bridges under heavy moving vehicles. J Sound Vib 355:264-283. https://doi.org/10.1016/j.jsv.2015.06.026

Carroll S, Owen J, Hussein M (2013) Reproduction of lateral ground reaction forces from visual marker data and analysis of balance response while walking on a laterally oscillating deck. Eng Struct 49:1034-1047

Charles P et al (2006) Foot-bridges. Assessment of vibrational behaviour of footbridges under pedestrian loading. Guide- line. SETRAAFGC

Clarke JL (1996) Structural design of polyme composites: EUROCOMP design code and handbook. Design code. London: European Structural Polymeric Composites Group

Clough R, Penzien J (1993) Dynamics of structures, 2nd edn. McGraw-Hill, London

Dallard P et al (2001) The London millennium footbridge. Structural Engineer 79(22):17-33

Danbon F, Grillaud G (2005) Dynamic behaviour of a steel footbridge. Characterisation and modelling of the dynamic loading induced by a moving crowd on the Solferino footbridge in Paris. In: Footbridge 2005, second international conference, Venice, Italy

Daniel Y, Lavan O, Levy R (2011) Multiple-tuned mass dampers for multimodal control of pedestrian bridges. J Struct Eng 138(9):11731178

Feldmann M, Heinemeyer C, Lukic M (2008) Human-induced vibration of steel structures, HIVOSS

Fujino P, Pacheco B, Nakamura S, Warnitchai P (1993) Synchronization of human waking observed during lateral vibration of a congested pedestrian bridge. Earthq Eng Struct Dyn 22(9):741-758

Garcia-Troncoso N, Ruiz-Teran A, Stafford P (2017) Dynamic response of girder footbridges with supplemental damping. In: Footbridge 2017, sixth international conference, Berlin, Germany

Heinemeyer C, Feldmann M (2008) European design guide for footbridge vibration. In: Footbridge 2008, third international conference, Porto, Portugal

Helbing D, Molnar P (1995) Social force model for pedestrian dynamics. Phys Rev E 51(5):4282

Ingólfsson ET, Georgakis CT, Ricciardelli F, Jonsson J (2011) Experimental identification of pedestrian-induced lateral forces on footbridges. J Sound Vib 330:1265-1284

ISO (2005) ISO 10137:2007. Basis for design of structures. Serviceability of buildings and pedestrian structures againts vibration. ISO, committee draft. International Organisation for Standards, Geneva

Jimenez-Alonso JF, Sáez A, Caetano E, Magalhãe F (2016) Vertical crowd-structure interaction model to analyze the change of the modal properties of a footbridge. J Bridge Eng 21(524):C4015004

Jones R, Pretlove A (1981) Two case studies in the use of tuned vibration absorbers on footbridges. Struct Eng, 59B(2)

Krenk S, Brønden A, Kristensen A (2005) Placement and tuning of resonance dampers on footbridges. In: Footbridge 2005, second international conference, Venice, Italy

Low A (2008) Design for dynamic effects in long span footbridges. In: Proceedings of footbridge 2008, third international conference, Porto, Portugal

Macdonald J (2009) Lateral excitation of bridges by balancing pedestrians. Proc R Soc A Math Phys Eng Sci 465(2104):1055-1073

Meinhardt C (2008) Application of tuned mass dampers for bridge decks. In: Footbridge 2008, third international conference, Porto, Portugal

Meinhdart C, Newland D, Talbot J, Taylor D (2017) Vibration performance of London's millennium. In: 24th international congress on sound and vibration, London, United Kingdom

Mevada H, Patel D (2015) Experimental determination of structural damping of different materials. In: 12th international conference on vibration problems. ICOVP

Nakamura S (2004) Model for lateral excitation of footbridges by synchronous walking. J Struct Eng ASCE 130(1):32-37

Nishihara O, Asami T (2002) Closed-form solutions to the exact optimizations of dynamic vibration absorbers (minimizations of the maximum amplitude magnification factors). J Vib Acoust 124(4):576-582

Pizzimenti AD, Ricciardelli F (2005) Experimental evaluation of the dynamic lateral loading of footbridges by walking pedestrians. In: Soize C, Schueller G (eds) 6th European conference on structural dynamics EURODYN 2005. Ed. by C. Soize and G. Schueller. Paris

Ramos C, Ruiz-Teran AM, Stafford PJ (2014) Footbridge response: improved understanding through probabilistic interpretation. In: Footbridge 2014 - past, present and future, London, UK

Ramos C, Ruiz-Teran AM, Stafford PJ (2017) Serviceability response of a benchmark cable-stayed footbridge: comparison of available methods' prediction. In: Footbridge 2017 - tell a story, Berlin, Germany 
Ramos C, Ruiz-Teran AM, Stafford PJ (2020) Guidance for footbridge design: a new method for the accurate evaluation of response in serviceability conditions. Adv Bridge Eng (accepted)

Ramos-Moreno C, Ruiz-Teran AM, Stafford PJ (2019) Impact of stochastic representation of pedestrian actions on serviceability response. ICE proceedings (accepted)

Schlaich M, Brownlie K, Conzett J, Sobrino J, Strasky J, Takenouchi K (2005) Guidelines for the design of foot-bridges, fib Bulletin No. 32, Lausanne.

Soong T, Dargush G (1997) Passive Energy Dissipation Systems in Structural Engineering, Wiley, Chichester and New York

Tilly G, Cullington D, Eyre R (1984) Dynamic behaviour of footbridges. IABSE 26:12-24

Townsend M (1985) Biped gait stabilization via foot placement. J Biomech 18:21-38

Tubino F, Piccardo G (2015) Tuned mass damper optimization for the mitigation of human-induced vibrations of pedestrian bridges. Meccanica 50(3):809-824

Umashankar KS, Abhinav A, Gangadharan KV, Vijay D (2009) Damping behaviour of cast and sintered aluminium. ARPN J Eng Appl Sci 4(6):66-71

Van Nimmen K, Lombaert G, De Roeck G, Van den Broeck P (2014) Vibration serviceability of footbridges: evaluation of the current codes of practice. Eng Struct 59:448-461

VanRossum G, Drake FL (2010) Python language reference manual. Network Theory Ltd, Bristol. https:/scholar.google.com/scholar_ lookup?title=Python\%20language\%20reference\%20manual\&publication_year=2011\&author=Rossum\%2CG\&author=Drake\%2CFL

Warburton G (1982) Optimum absorber parameters for various combinations of response and excitation parameters. Earthq Eng Struct Dyn 10(3):381-401

Weber B, Feltrin G (2010) Assessment of long-term behavior of tuned mass dampers by system identification. Eng Struct 32(11):3670-3682

Wei X, Russell J, Živanović S, Toby Mottram J (2019) Measured dynamic properties for FRP footbridges and their critical comparison against structures made of conventional construction materials. Compos Struct 223:110956

Živanović S, Feltrin G, Mottram J, Brownjohn J (2014) Vibration performance of bridges made of fibre reinforced polymer. In: Catbas F (ed) Dynamics of civil structures, vol 4, pp 155-162

Živanović S, Pavic A, Reynolds P (2007) Probability-based prediction of multi-mode vibration response to walking excitation. Eng Struct 29(6):942-954

\section{Publisher's Note}

Springer Nature remains neutral with regard to jurisdictional claims in published maps and institutional affiliations.

\section{Submit your manuscript to a SpringerOpen ${ }^{\circ}$ journal and benefit from:}

- Convenient online submission

- Rigorous peer review

- Open access: articles freely available online

- High visibility within the field

- Retaining the copyright to your article

Submit your next manuscript at $\boldsymbol{s p r i n g e r o p e n . c o m ~}$ 